\title{
O ENSINO DE ESTATíSTICA E PROBABILIDADE POR MEIO DE JOGOS E ReSOluÇÃo de PRoblemas diante dos deSAFIOS do PROCESSO dE FORMAÇÃO DOCENTE
}

\author{
THE PROBABILITY AND STATISTICS TEACHING BY GAMES AND PROBLEM SOLUTION \\ THROUGH THE TEACHERS' TRAINING CHALLENGES
}

\author{
LA ENSEÑANZA DE ESTADÍSTICA Y PROBABILIDAD POR MEDIO DE JUEGOS Y \\ RESOLUCIÓN DE PROBLEMAS FRENTE A LOS DESAFÍOS DEL PROCESO DE FORMACIÓN \\ DOCENTE
}

\author{
Beatriz Cristina da Silva Delalibera \\ E-mail: beatriz delalibera@yahoo.com.br \\ Aline Resende Gomes \\ E-mail: aline_r_gomes@hotmail.com \\ Daniel Fernando Bovolenta Ovigli \\ E-mail: daniel.ovigli@uftm.edu.br
}

Universidade Federal do Triângulo Mineiro - UFTM

\section{RESUMO}

O curso de formação inicial tem a responsabilidade de cumprir o desafio de preparar professores para uma educação significativa, que possibilite ao aluno interpretar e fazer conclusões por meio das mensagens disponibilizadas, auxiliando-o a se constituir em um cidadão capaz de tomar decisões. Para colaborarmos com as discussões sobre as contribuições dos cursos de licenciatura para o ensino de Probabilidade e Estatística, realizamos uma pesquisa bibliográfica de cunho qualitativo. Com a investigação notamos indicativos de que o ensino da Estatística e Probabilidade não pode ser realizado por meio de fórmulas e reproduções. Em uma vertente mais atual o professor assume o papel de mediador e incentivador no processo de construção do conhecimento ao proporcionar situações didáticas que desafiem e estimulem seus alunos mediante metodologias, a exemplo de resolução de problemas e jogos, o que também pode contribuir no processo de formação do professor a partir da reflexão sobre sua prática.

PALAVRAS-CHAVE: Formação inicial. Jogos. Resolução de problemas.

\section{ABSTRACT}

The initial teacher training has the responsibility of solving the teachers training for meaningful education which enables the student to interpret and make conclusions through available messages, helping him/her to become a capable citizen to make decisions. In order to collaborate with the discussions about the undergraduate course contributions for the Probability and Statistics teaching, we have carried out a qualitative bibliographical research. With the investigation we have indications that the Statistics and Probability teaching cannot be done through formulas and reproductions. In a more current way, the teacher assumes the mediator role and give support in knowledge construction process by providing didactic situations which challenge and stimulate their students through methodologies, such as problem solving and games, which can also contribute to the teacher training process from the reflection on their practice.

KEYWORDS: Initial training. Games. Problem solving. 


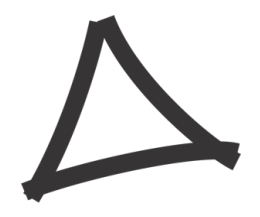

Revista Triângulo

www.seer.uftm.edu.br/revistaeletronica

El curso de formación inicial tiene la responsabilidad de cumplir el desafio de preparar profesores para una educación significativa que posibilite al alumno interpretar y hacer conclusiones por medio de mensajes disponibles, auxiliándolo a constituirse en un ciudadano capaz de tomar decisiones. Para colaborarnos con las discusiones sobre las contribuciones de los cursos de formación docente para la enseñanza de Probabilidad y Estadística, realizamos una investigación bibliográfica de cuño cualitativo. Con la investigación notamos indicativos de que la enseñanza de Estadística y Probabilidad no puede ser realizada por medio de fórmulas y reproducciones. En un tratado más actual, el profesor asume el papel de mediador e incentivador en el proceso de construcción del conocimiento al proporcionar situaciones didácticas que desafien y estimulen sus alumnos mediante metodologías, a ejemplo de la resolución de problemas y juegos, lo que también puede contribuir en el proceso de formación del profesor a partir de la reflexión sobre su práctica.

PALABRAS-CLAVE: Formación inicial. Juegos. Resolución de problemas

\section{INTRODUÇÃO}

1.1 A formação inicial de professores e o desafio da construção de um ensino significativo

O ambiente escolar deveria oferecer aos estudantes um aprendizado significativo, o que nos faz refletir sobre a necessidade de promover práticas docentes que sejam relevantes e que levem o aluno a construir seu conhecimento. Diante desta perspectiva, percebemos o quanto é importante os cursos de formação de professores darem suporte e prepararem professores comprometidos com uma educação de qualidade e eficaz; professores que, como cita Pimenta (2012), são necessários para mediar nos processos de constituição da cidadania dos alunos.

A formação inicial deveria dar suporte para que o professor tenha possibilidade de promover a construção do conhecimento dos alunos da Educação Básica. Para que isso ocorra, as disciplinas que compõem os cursos de graduação deveriam colaborar para a construção do perfil do futuro professor no sentido de permitir que os graduandos tenham acesso a experiências, dificuldades e desafios da escola, possibilitando que eles reflitam sobre a teoria e prática.

Porém, como cita Gatti (2012), o que vemos nos cursos de formação inicial são disciplinas apresentadas de maneira fragmentada nas licenciaturas, o que faz com que as aulas sejam direcionadas com matérias específicas e, consequentemente, os graduandos tendem a dispensar preocupações com o preparo pedagógico-didático (SAVIANI, 2009), distanciando ainda mais do que seria ideal para as escolas. Há, então, o desenvolvimento de um currículo formal com conteúdos e atividades de estágio distanciados da realidade escolar, como traz Pimenta (2012). 


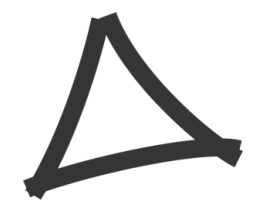

Revista Triângulo

www.seer.uftm.edu.br/revistaeletronica

Atualmente a escola tem o importante papel de dar possibilidade ao aluno de transformar as mensagens disponibilizadas pela mídia em conhecimento. A sociedade está mergulhada em uma gama de informações que são acessadas facilmente pelos leitores, o grande problema é que grande parte desses dados são disponibilizados em forma de gráficos, tabelas e registros numéricos que devem ser interpretados para que não sejam manipulados de acordo com interesses políticos e econômicos. Frente a estas considerações, assumimos como objetivo deste artigo trazer descrever características a serem desenvolvidas pelo professor que ensina Probabilidade e Estatística na Educação Básica discutindo, em particular, jogos e Resolução de Problemas como formas de abordagem do tema.

\section{REFERENCIAL TEÓRICO}

A presença constante da Estatística em revistas, jornais, enfim, informações veiculadas por meio da internet, nos fazem acreditar que o letramento estatístico, definido por Gal (2002, apud MORENO; CAZORLA, 2015, p.108) como "habilidade para interpretar e avaliar criticamente informações estatísticas" se faz necessário para que os cidadãos possam tomar decisões. Dessa maneira, podemos considerar que a Educação Estatística não pode acontecer por meio de memorização de fórmulas e exercícios descontextualizados. Segundo Evangelista e Guimarães $(2015$, p. 81$)$ podemos dizer que:

O reconhecimento da importância da Estatística em nossa sociedade vem aumentando nos últimos anos. A crescente utilização dos recursos estatísticos se deve principalmente aos avanços tecnológicos apresentados pela sociedade, os quais possibilitam lidarmos com uma grande quantidade de informações.

É inegável o avanço tecnológico que vem acontecendo ultimamente, no mesmo compasso vemos uma sociedade que se modifica à medida em que a tecnologia se torna disponível e acessível a todos, pois são imensuráveis as maneiras que podemos adquirir conhecimento. Para Lopes (2008, p. 60) diante dessa rápida mudança “é imprescindível o conhecimento da probabilidade de ocorrência de acontecimentos para agilizarmos a tomada de decisão e fazermos previsões". 


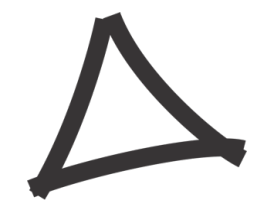

Revista Triângulo

www.seer.uftm.edu.br/revistaeletronica

De acordo com Magalhães (2015), para sermos cidadãos plenos é necessário entendermos tabelas, gráficos, perceber limitações numéricas sobre os assuntos, compreender a aleatoriedade em eventos e infelizmente essas habilidades ainda não fazem parte do cotidiano da maioria da população.

Assim como a Estatística, podemos observar situações em nosso dia a dia que se remetem à Probabilidade. De acordo com os PCN (BRASIL, 1997), a principal finalidade para seu estudo é que o aluno compreenda que grande partes dos acontecimentos do cotidiano são de natureza aleatória e é possível identificar prováveis resultados desses acontecimentos. "As noções de acaso e incerteza, que se manifestam intuitivamente, podem ser exploradas na escola, em situações nas quais o aluno realiza experimentos e observa eventos" (BRASIL, 1997, p. 56).

Além de ser constante nas situações em nosso cotidiano, Fonseca (2013) ressalta que o aprendizado do cálculo de Probabilidade é muito importante à devido sua utilização em Estatística, Física, Ciências Sociais e no exercício de sua cidadania. Assim, seu ensino deve ser construído pelo próprio aluno e o professor assume o papel de mediador e orientador no processo de ensino-aprendizagem.

A Estatística e a Probabilidade se tornam cada vez mais presentes na vida cotidiana e, desta maneira, seu ensino não pode ser destoado da realidade, tampouco um emaranhado de fórmulas e procedimentos sem sentido para o aluno:

Não basta ao cidadão entender as porcentagens expostas em índices estatísticos, como o crescimento populacional, taxas de inflação, desemprego... É preciso analisar/relacionar criticamente os dados apresentados, questionando/ponderando até mesmo sua veracidade. Assim como não é suficiente ao aluno desenvolver a capacidade de organizar e representar uma coleção de dados, faz-se necessário interpretar e comparar esses dados para tirar conclusões (LOPES, 2008, p. 60).

As habilidades necessárias para solucionar problemas que envolvem Estatística e Probabilidade estão longe de serem atribuídas à mera aplicação de fórmulas ou reprodução de exercícios e, diante desse fato, será que o professor recém-formado possui as características que promoverão um ensino Estatística e Probabilidade de maneira significativa para os alunos? 


\section{MATERIAIS E MÉTODOS}

Delinear esse estudo com base nas características da pesquisa qualitativa nos dá suporte para analisarmos situações que surgem por meio das mudanças de nossa sociedade, em particular, acontecimentos que ocorrem na sala de aula em relação ao ensino de Estatística e Probabilidade.

Laville e Dionne (1999), ao nos colocar a par sobre o surgimento das Ciências Humanas, esclarece que esta surge a partir da qualificação dos problemas e necessidades ocasionadas por profundas mudanças nas sociedades ocidentais a partir da segunda metade do século XIX. Deste modo, utilizar uma pesquisa de cunho qualitativo nos remete às palavras de Bogdan e Biklen (1994): ao conduzirmos uma investigação estamos promovendo um diálogo entre o pesquisador e os sujeitos da pesquisa, estabelecendo que o investigador articule "estratégias e procedimentos que lhes permitam tomar em consideração as experiências do ponto de vista do informador" (p. 51).

Com a intenção de abordarmos as questões sobre a formação inicial dos professores e as aptidões necessárias deste profissional para ensinar Estatística e Probabilidade na Educação Básica, optamos em realizar este estudo exploratório. Conforme Gil (1989), trata-se de uma pesquisa utilizada para promover uma visão geral referente a um determinado fato e por ela se caracterizar em ser "a primeira etapa de uma investigação mais ampla" (p. 44). Segundo o autor, esse tipo de estudo envolve o levantamento bibliográfico.

Gil (1989) também afirma que a pesquisa bibliográfica é realizada mediante material já elaborado (fontes bibliográficas), em livros, revistas científicas, teses e relatórios de pesquisa.

Tendo acesso às referências, fizemos uma leitura que nos possibilitasse sistematizar pontos importantes ressaltados pelos autores, em consonância com nosso tema. Após as análises dos tópicos elencados e inferências dos dados, chegamos às conclusões desse trabalho procurando responder aos objetivos colocados.

\section{ANÁLISE DOS DADOS E RESULTADOS}




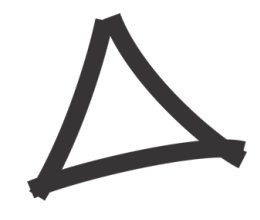

4.1 Os jogos e a resolução de problemas para o ensino de estatística e probabilidade

Os jogos e a resolução de problemas vêm sendo introduzidos como metodologia no ensino da matemática. Polya (1995) destaca que ao resolver um problema há sempre uma pitada de descoberta, pois essa metodologia desafia a curiosidade. Segundo o autor, a resolução de problemas é uma oportunidade para que os professores possam desafiar a curiosidade dos alunos por meio de perguntas estimulantes para que alcancem seus objetivos por meio do gosto pelo raciocínio independente.

Os Parâmetros Curriculares Nacionais (BRASIL, 1997; BRASIL, 1998) do primeiro e segundo ciclos também mencionam a necessidade de compreensão das informações veiculadas para que os alunos possam tomar decisões que influenciarão suas vidas pessoais e o contexto social no qual estão inseridos. Desta maneira, ainda de acordo com os Parâmetros, estar alfabetizado engloba também saber ler e interpretar dados e, assim, a abordagem dos tópicos de Estatística, Análise Combinatória e Probabilidade devem estar presentes desde os ciclos iniciais (BRASIL, 1997, p. 84).

A principal finalidade para o estudo de Probabilidade, segundo os PCN, é a de que o aluno compreenda que grande parte dos acontecimentos do cotidiano são de natureza aleatória e é possível identificar prováveis resultados destes acontecimentos. As noções de acaso e incerteza, que se manifestam intuitivamente, podem ser exploradas na escola, em situações nas quais o aluno realiza experimentos e observa eventos (BRASIL, 1997, p. 56).

Ainda de acordo com o documento (BRASIL, 1998), o Tratamento da Informação é importante tanto para aspectos de uma cultura básica, quanto para atividades profissionais. Desta maneira é justificável a possibilidade de desenvolvimento do raciocínio para resolver situações-problema nas quais é necessário coletar, organizar, interpretar dados e amostras e apresentar resultados por meio da linguagem estatística.

Assuntos como economia, saúde, educação, política, etc. são mostrados a todo o momento pela mídia por meio de gráficos, tabelas, diagramas e fluxogramas, além disso estes assuntos despertam interesse dos jovens para questões sociais e “(...) se tornam significativos contextos utilizados para aprendizagem de conceitos e procedimentos matemáticos" (BRASIL, 1998, p. 134). 


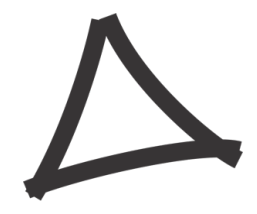

Revista Triângulo

www.seer.uftm.edu.br/revistaeletronica

O ensino da Estatística e Probabilidade por meio de resolução de problemas e jogos nos faz refletir sobre os dizeres de Freire (1987), para quem o papel do educador problematizador é proporcionar, com os educandos, as condições para o verdadeiro conhecimento. A prática bancária é apenas uma anestesia que inibe a criatividade dos alunos, a educação problematizadora liberta, ao contrário da bancária que domina.

Quanto mais se problematizam os educandos, como seres no mundo e com o mundo, tanto mais se sentirão desafiados. Tão mais desafiados, quanto mais obrigados a responder ao desafio. Desafiados, compreendem o desafio na própria ação de captá-lo. Mas, precisamente porque captam o desafio como um problema em suas conexões com outros, num plano de totalidade e não como algo petrificado, a compreensão resultante tende a tornar-se crescentemente crítica, por isto, cada vez mais desalienada (FREIRE, 1987, p. 40).

Para que o ensino da Estatística e Probabilidade se torne significativo, as Orientações Educacionais Complementares aos Parâmetros Curriculares Nacionais do Ensino Médio (BRASIL, 2000) mencionam a utilização de jogos como estratégias de aprendizagem, destacando que:

Os jogos e brincadeiras são elementos muito valiosos no processo de apropriação do conhecimento. Permitem o desenvolvimento de competências no âmbito da comunicação, das relações interpessoais, da liderança e do trabalho em equipe, utilizando a relação entre cooperação e competição em um contexto formativo. $\mathrm{O}$ jogo oferece o estímulo e o ambiente propícios que favorecem o desenvolvimento espontâneo e criativo dos alunos e permite ao professor ampliar seu conhecimento de técnicas ativas de ensino, desenvolver capacidades pessoais e profissionais para estimular nos alunos a capacidade de comunicação e expressão, mostrandolhes uma nova maneira, lúdica e prazerosa e participativa, de relacionar-se com o conteúdo escolar, levando a uma maior apropriação dos conhecimentos envolvidos (BRASIL, 2000, p.56).

O ensino de Estatística e Probabilidade de maneira libertadora e investigativa proporciona aos educandos a possibilidade de refletir sobre as informações acessadas pelas tecnologias digitais. Esta reflexão é o que garante a compreensão da realidade e busca de soluções para que o aluno se torne crítico e participativo de sua história, cultura e sociedade. Onuchic e Allevato (2011) destacam que, por meio da Resolução de Problemas, os alunos são levados a fazer conexões entre diversos ramos da Matemática. Dessa maneira, eles são 


\section{$\Delta$}

capazes de construir novos conhecimentos, mas é necessário que professores e alunos tomem novas atitudes em sala de aula:

O professor precisa preparar, ou escolher, problemas apropriados ao conteúdo ou ao conceito que pretende construir. Precisa deixar de ser o centro das atividades, passando para os alunos a maior responsabilidade pela aprendizagem que pretendem atingir. Os alunos, por sua vez, devem entender e assumir essa responsabilidade. Esse ato exige de ambos, portanto, mudanças de atitude e postura, o que, nem sempre, é fácil conseguir (p.82).

Entretanto, Onuchic e Allevato (2011, p. 82) afirmam que há boas razões para se trabalhar com resolução de problemas destacando que:

- Resolução de problemas coloca o foco da atenção dos alunos sobre as ideias matemáticas e sobre o dar sentido.

- Resolução de problemas desenvolve poder matemático nos alunos, ou seja, capacidade de pensar matematicamente, utilizar diferentes e convenientes estratégias em diferentes problemas, permitindo aumentar a compreensão dos conteúdos e conceitos matemáticos.

- Resolução de problemas desenvolve a crença de que os alunos são capazes de fazer matemática e de que a Matemática faz sentido; a confiança e a autoestima dos estudantes aumentam.

- Resolução de problemas fornece dados de avaliação contínua, que podem ser usados para a tomada de decisões instrucionais e para ajudar os alunos a obter sucesso com a matemática.

- Professores que ensinam dessa maneira se empolgam e não querem voltar a ensinar na forma dita tradicional. Sentem-se gratificados com a constatação de que os alunos desenvolvem a compreensão por seus próprios raciocínios.

- A formalização dos conceitos e teorias matemáticas, feita pelo professor, passa a fazer mais sentido para os alunos.

Com base no que foi exposto, pode-se afirmar que o ensino por meio da Resolução de Problemas, de acordo com Onuchic e Allevato (2011), se torna propício para a construção do conhecimento matemático por meio da observação e percepção de padrões, especialmente quando o problema proposto contribui para gerar novos conceitos e conteúdos matemáticos.

De acordo com Marim e Barbosa (2010), na metodologia tradicional comumente utilizada para o ensino da Matemática, espera-se que os alunos sejam capazes de realizar reproduções do que foi aprendido. Segundo os autores, "este método não é eficaz, pois podese dizer que o aluno aprendeu apenas reproduzir mecanicamente, mas que não aprendeu o conteúdo e não sabe utilizá-lo, ou seja, não aprendeu a descontextualizar este conteúdo e a contextualizá-lo em uma nova situação" (p. 228). 


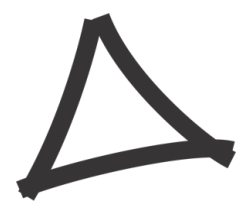

Revista Triângulo

www.seer.uftm.edu.br/revistaeletronica

Outra metodologia de ensino que pode contribuir para o ensino de Estatística e Probabilidade de maneira promissora e significativa é a utilização de jogos e, desta maneira, podemos associá-la com a Resolução de Problemas. De acordo com Grando (2000, p.32):

[...] o cerne da resolução de problemas está no processo de criação de estratégias e na análise, processada pelo aluno, das várias possibilidades de resolução. No jogo ocorre fato semelhante. Ele representa uma situaçãoproblema determinada por regras, em que o indivíduo busca, a todo o momento, elaborando estratégias e reestruturando-as, vencer o jogo, ou seja, resolver o problema. Esse dinamismo característico do jogo é o que possibilita identificá-lo no contexto da resolução de problemas.

Podemos destacar, ainda, que, para Grando (1995, p. 78):

[...] o jogo como resolução de problemas possibilita a investigação, ou seja, a interação e exploração do conceito através da estrutura matemática subjacente ao jogo e que pode ser vivenciada, pelo aluno, quando ele joga, elaborando estratégias e testando-as a fim de vencer o jogo. Neste sentido, defende-se a inserção dos jogos no contexto educacional numa perspectiva de resolução de problemas, garantindo ao processo educativo os aspectos que envolvem a exploração, aplicação e explicitação do conceito vivenciado.

Moura (1992) destaca que quando o professor opta por utilizar o jogo em sala de aula tem a intenção de proporcionar a aprendizagem de um conteúdo ou habilidade, sendo assim o autor afirma que o jogo escolhido deve atender o objetivo de levar o aluno do conhecimento primeiro ao conhecimento elaborado.

Para o autor, os jogos e a Resolução de Problemas possuem características semelhantes enquanto estratégias de ensino, como por exemplo, a vontade de jogar e de resolver um problema. Por fim, versa que é possível combinar jogo e Resolução de Problemas, mas que para isso é necessário que haja uma intenção do professor:

[...] é possível combinar jogo e resolução de problemas nas séries iniciais; porém, fazer isto é muito mais que uma simples atitude, é uma postura que deve ser assumida na condução do ensino. E assumi-la com vistas ao desenvolvimento de conceitos científicos exige um projeto de ensino, inserido no projeto coletivo da Escola. Fazer isto é dar um sentido humano ao jogo, à resolução de problemas e, sendo assim, à Educação Matemática (MOURA, 1992, p. 52).

Conforme Ribeiro (2009), a inserção dos jogos se torna um significativo processo de ensino-aprendizagem, o ato de brincar e/ou jogar é inerente ao ser humano e essencial ao 


\section{$\Delta$}

desenvolvimento das crianças. A autora ressalta que no ensino de Matemática o jogo pode ser realizado como uma atividade de Resolução de Problemas que pode permitir ao aluno analisar, levantar hipóteses, fazer conjecturas, propor estratégias e soluções. Diante dessa perspectiva, Resolução de Problemas pode ser considerada como ponto de partida para que se desenvolva criatividade e autonomia dos alunos. Ribeiro (2009) também aponta que os jogos podem potencializar aspectos de ordem afetiva, social e cognitiva.

Diante dessas afirmativas, Marim e Barbosa (2010) destacam que os alunos devem ser considerados como agentes da construção de seu conhecimento, pois devem ser capazes de utilizar os conceitos já aprendidos na resolução de problemas.

Vimos, então, que uma maneira de modificar a metodologia tradicional é a utilização de jogos e Resolução de Problemas nas aulas de Matemática. Smole e colaboradores (2007) afirmam que o trabalho com jogos "quando bem planejado e orientado auxilia no desenvolvimento de habilidades como observação, análise, levantamento de hipóteses, busca de suposições, reflexão, tomada de decisão, argumentação e organização" (p. 10).

Com os avanços tecnológicos percebemos que as informações são facilmente acessadas, porém poucas pessoas desenvolvem habilidades para interpretar as mensagens que são disponibilizadas em gráficos e tabelas. A mera transmissão de informação já não é o bastante para prepararmos os jovens para solucionar problemas. A proposta colocada aqui é uma maneira que torna o aluno o personagem principal no processo de ensino-aprendizagem.

Quando um problema é apresentado ao estudante, o professor não pode mostrar qual é a resposta, mas deve intermediar para que o aluno consiga, a partir da investigação e curiosidade, chegar à solução do seu problema. Dessa maneira, jogos e Resolução de Problemas pode se tornar eficaz no que diz respeito à formação de cidadãos críticos e que saibam interpretar a avalanche de informações disponibilizadas a cada segundo por meio dos meios de comunicação a partir de gráficos, tabelas e dados numéricos.

Para Lopes (2008) somos levados a ter acesso informações dos contextos social e econômico que fazem parte do cotidiano dos cidadãos cada vez mais cedo. Geralmente estes dados nos são apresentados por uma síntese de informações que contém tabelas e gráficos. Para a autora, a escola se encontra na necessidade de proporcionar aos alunos uma formação que contribua para o exercício da cidadania entendida como "capacidade de atuação reflexiva, ponderada e crítica de um indivíduo em seu grupo social” (p 60). 


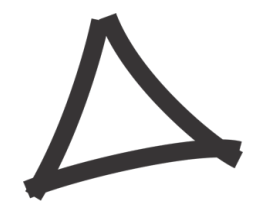

Revista Triângulo

www.seer.uftm.edu.br/revistaeletronica

Portanto, jogos e Resolução de Problemas tornam-se metodologias que vêm sendo discutidas em pesquisas para que, de fato, ocorra um ensino de Probabilidade e Estatística mais significativo e que será utilizado no cotidiano dos alunos. Mas, para que isso seja possível, é necessário que haja uma reformulação no processo de formação inicial dos professores:

O conhecimento profissional didático deverá incorporar o domínio de conceitos, representações, procedimentos, resolução de problemas, habilidades de exploração e investigação. Necessita que o docente tenha boa relação com a matemática, gosto e disponibilidade para se envolver em preparação das aulas, para refletir sobre os redirecionamentos no decorrer das aulas e durante momentos de formação e trabalho colaborativo. Urge o desenvolvimento de projetos de formação inicial e contínua de professores que abordem o trabalho com a estocástica ${ }^{1}$ nas aulas de matemática da educação básica (LOPES, 2008, p. 71 - 72).

4.2 $\mathrm{O}$ desafio de formar a identidade docente de um professor que promove um ensino significativo

Muitas são as mudanças em nosso cotidiano, de ordem política, econômica ou social. Em meio a essas transformações está a escola e, consequentemente, os cursos de formação inicial.

$\mathrm{O}$ professor precisa estar atento às singularidades dos alunos e perceber que essa heterogeneidade da sala de aula deve se tornar em lugar propício para desenvolver habilidades. Isso faz com que os professores não sejam simplesmente meros transmissores de conhecimento, conforme pontuam Borges, Aquino e Puentes (2011, p. 110):

[...] devemos nos manter esperançosos e ativos perante os desafios e na luta contra o sistema de exclusão social, que enfraquece as bases de sustentação democrática, restringindo o direito à educação, que é pré-requisito essencial para a conquista da cidadania.

Segundo Gatti, Barreto e André (2011), o papel de um professor é proporcionar ao aluno aprendizagens que sejam significativas para que se superem desvantagens sociais. Para que isso ocorra, as autoras destacam por Tedesco (2005, apud GATTI; BARRETO; ANDRÉ, 2011) que o professor deve acreditar no projeto da educação e na capacidade dos alunos. Nesse contexto nos deparamos com os dizeres de Gatti, Barreto e André (2011, p. 24):

Aqui, o fator humano - quem ensina, quem aprende, quem faz a gestão do sistema e da escola e de quem a forma - destaca-se como polo de atenção 


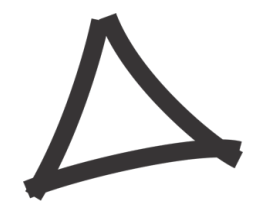

dos vários grupos envolvidos na busca de nova posição social e de novas condições para suas relações sociais de convivência e de trabalho.

Para Pimenta (2012), o professor é responsável pelo processo de humanização dos alunos. Então, segundo a autora, espera-se que a licenciatura desenvolva conhecimentos, habilidades, atitudes e valores que contribuem para construção de seus saberes-fazeres docentes de acordo com as necessidades e desafios do cotidiano:

Espera-se, pois, que mobilize os conhecimentos da teoria da educação e da didática necessários à compreensão do ensino como realidade social, e que desenvolva neles a capacidade de investigar a própria atividade para, a partir dela, constituírem e transformarem os seus saberes-fazeres docentes, num processo contínuo de construção de suas identidades como professores (p. 19).

A identidade do professor está diretamente ligada às relações emocionais, experiências e informações recebidas ao longo de seu processo de formação. Desta maneira, podemos considerar que o processo de formação de um professor jamais poderá ser declarada encerrada.

Levando em consideração que a formação do professor é permanente, podemos observar que esse percurso acontece também quando, conforme Bolívar (2006), o docente é imerso em um processo de reformulação de uma identidade, que ocorre dentro do grupo social no qual está inserido. Sendo assim, o professor assimila saberes, práticas e sentimentos e, ao mesmo tempo, tenta buscar reconhecimento por parte dos colegas da profissão, alunos e familiares e isso tudo contribui para suas reflexões diante de sua prática e saberes docente. Neste caso Medina e Domínguez (1989) apud Garcia (1999, p. 23) consideram:

[...] a formação de professores como preparação e emancipação profissional do docente para realizar crítica, reflexiva e eficazmente um estilo de ensino que promova uma aprendizagem significativa nos aluno e consiga um pensamento inovador, trabalhando em equipe com os colegas para desenvolver um projeto educativo comum.

Segundo Dubar (2005), a identidade é formada quando o indivíduo é colocado em situações nas quais há interações sociais. Ciampa (1998) cita que estamos em incessante transformação em relação às condições históricas e materiais que nos são impostas e, sendo assim, as individualidades não podem ser tratadas como algo independente, elas dependerão do meio no qual estamos inseridos, da coletividade, da cultura e do processo histórico que 


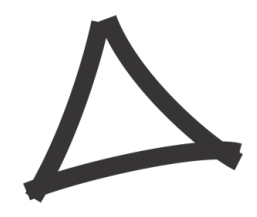

Revista Triângulo

www.seer.uftm.edu.br/revistaeletronica

fazem parte de nosso cotidiano. Com isso, mesmo em constante transformação influenciada por aspectos coletivos, conseguimos também ser individuais.

Diante dos desafios que compõem o ambiente escolar e a formação do professor, podemos entender a importância da auto-reflexão, das experiências, do conhecimento dos conteúdos específicos e pedagógicos que integram os saberes docentes e que contribuem para uma aprendizagem significativa diante de tantos obstáculos presentes no processo de construção do conhecimento.

Ao analisarmos as barreiras que impedem o ensino de Probabilidade e Estatística nos deparamos com uma formação inicial que, segundo Lopes (2008), "não incorpora um trabalho sistemático sobre estocástica, dificultando a possibilidade desses profissionais desenvolverem um trabalho significativo com essa temática nas salas de educação básica" (p. 70).

Para Lopes (2008) o ensino de Probabilidade integrada à Estatística envolve "a construção de modelos de fenômenos físicos, desenvolvimento e uso de estratégia de simulação e a comparação e a avaliação de problemáticas diversas" (p. 69), o que nos faz associar essa abordagem como resolução de problemas mas, para a autora, para que haja um trabalho significativo, esses aspectos devem estar presentes também na formação dos professores:

A resolução de problemas, que é o princípio norteador da aprendizagem da matemática, pode possibilitar o desenvolvimento do trabalho com estatística e probabilidade em sala de aula, pois da mesma forma que a matemática, a estatística também se desenvolveu através da resolução de problemas de ordem prática na história da humanidade. Assim, é preciso entender que problema não é um exercício de aplicação de conceitos recém-trabalhados, mas o desenvolvimento de uma situação que envolve interpretação e estabelecimento de uma estratégia para a resolução (p. 62).

O ensino de Estatística e Probabilidade requer habilidades de investigação e interpretação para analisar e comparar informações disponibilizadas praticamente em tempo real, promover o ensino significativo da Estocástica por meio da construção do conhecimento que utilize jogos e Resolução de Problemas. O professor, porém, se depara com uma realidade totalmente diferente daquela presenciada pelos bancos da instituição formadora, que raramente prepara o futuro docente no sentido de buscar novas metodologias de ensino e o professor se vê na situação de reproduzir o que foi ensinado na academia e dificilmente cumprirá com seu papel de promover transformação no processo de ensino e aprendizagem. 


\section{CONSIDERAÇÕES FINAIS}

É notória a presença da Estatística e da Probabilidade em nosso cotidiano, cada vez mais ela vem sendo utilizada em veiculações de informações por meio da mídia que acaba nos influenciando em tomadas de decisões. Desta maneira, é fundamental que tenhamos conhecimento nesta área para que não nos tornemos vulneráveis pois, como destacam Cazorla e Castro (2008, p.46), “a idoneidade dos discursos, propagandas, manchetes e notícias ganham credibilidade do cidadão comum por meio de números, gráficos ou tabelas e mesmo que haja questionamento sobre a veracidade de alguma informação, é necessário que esse cidadão seja instrumentalizado para arguir e contra argumentar".

Deste modo, a Estatística e a Probabilidade se tornam cada vez mais presentes na vida cotidiana, por isso seu ensino não pode ser algo destoado da realidade e nem deve ser um emaranhado de fórmulas e procedimentos sem sentido para o aluno. Diante disto, a proposta de utilização de jogos baseada em uma perspectiva de Resolução de Problemas permite uma forma de organizar o ensino envolvendo mais que aspectos puramente metodológicos, pois inclui toda uma postura frente ao que é ensinar e, consequentemente, ao que significa aprender (SMOLE, DINIZ e CÂNDIDO, 2007; SMOLE, DINIZ e MILANI, 2007; e SMOLE et al., 2008).

A mera transmissão de conhecimento por meio de fórmulas muitas vezes não condiz com a realidade dos alunos; sendo assim, o professor deve estar preparado para diferenciar seus métodos tornando as aulas mais prazerosas e relevantes.

Os saberes docentes vão se constituindo a partir de uma prática que busca vincular os conhecimentos escolares com o cotidiano dos alunos fazendo com que eles compreendam que o aprendizado é importante para sua formação como cidadãos autônomos, críticos e responsáveis.

Para promover um aprendizado significativo é necessário que o professor esteja consciente de seu papel transformador. Não há fórmulas mágicas ou receitas prontas que fazem com que um licenciando se torne educador, não há hora marcada e nem data certa para se formar, o processo de constituição do professor é lento, cheio de incertezas e obstáculos, 


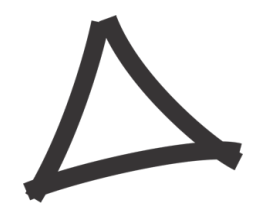

Revista Triângulo

www.seer.uftm.edu.br/revistaeletronica

porém, aquele que se dispõe a pensar, repensar, pesquisar e refletir sobre suas práticas poderá obter êxito em seu trabalho docente, pois tem compromisso com uma educação transformadora e libertadora.

${ }^{1}$ Estocástica é o termo utilizado para tratar a probabilidade integrada à estatística (LOPES, 2008, p. 72).

\section{REFERÊNCIAS}

BORGES, M. C.; AQUINO, O. F.; PUENTES, R. V. Formação de Professores no Brasil: história, políticas e perspectivas. In: Revista HISTEDBR On-line, Campinas, n.42, p.94-112, jun 2011. Disponível em: $<$ http://www.fae.unicamp.br/revista/index.php/histedbr/article/view/3301> Acesso em: 29 ago. 2017.

BRASIL. Parâmetros Curriculares Nacionais: Matemática. Secretaria de Educação Fundamental - Ensino de $1^{\mathrm{a}}$ a $4^{\mathrm{a}}$ série - Brasília: MEC / SEF, vol. 3,1997.

- Parâmetros Curriculares Nacionais: Matemática. Secretaria de Educação Fundamental - Ensino de $5^{\mathrm{a}}$ a $8^{\mathrm{a}}$ série - Brasília: MEC / SEF, vol. 3,1998.

- Parâmetros Curriculares Nacionais + $(\mathbf{P C N}+)$ - Ciências da Natureza e suas Tecnologias. Secretaria da Educação Média e Tecnológica. Brasília: MEC, 2002.

BOLÍVAR, A. Construcción de la identidad profesional del profesorado. In: La identidad profesional del profesorado de secundaria: crisis y reconstrucción. Málaga, España: Ediciones Aljibe, 2006, 57-80.

BOGDAN, R. BIKLEN, S. K. Investigação qualitativa em educação: uma introdução à teoria e aos métodos. Porto, Portugal: Editora Porto, 1994.

CAZORLA, I. M.; CASTRO, F. C. de. O papel da estatística na leitura do mundo: o letramento estatístico. Publicatio UEPG: Ciências Humanas, Linguísticas, Letras e Artes, Ponta Grossa, P. 45-53, jun. 2008. Disponível em: $<$ http://www.revistas2.uepg.br/index.php/humanas/article/view/617/605> Acesso em: 28 de ago. de 2017.

CIAMPA, A. C. Identidade humana como metamorfose: a questão da família e do trabalho e a crise de sentido no mundo moderno. V.III, $n^{\circ} 6$, Interações, 1998. Disponível em: $<$ http://www.siid.ucdb.br/docentes/downloads.php?Dir=arquivos\&File=140131.pdf $>$. Acesso em 13 de out. 2016. 


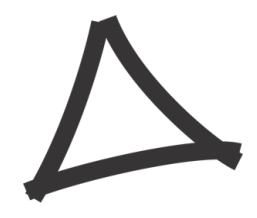

DELLA NINA, C. T. et al. Um currículo de matemática em movimento. Ruth Portanova (Org.). Porto Alegre: EDIPUCRS, 2005.

DUBAR, C. Para uma teoría sociológica da identidade.

A socialização: construção das identidades sociais e profissionais. Tradução Andréa Stahel M. da Silva. São Paulo: Martins Fontes, 2005.

EVANGELISTA, B.; GUIMARÃES, G. Aprendizagem de alunos do $5^{\circ}$ ano sobre escalas representadas em gráficos. In: SAMÁ, Suzi; SILVA, Mauren Porciúncula Moreira. (Org.). Educação estatística: ações e estratégias pedagógicas no ensino básico e superior. Curitiba, PR: CRV, 2015.

FONSECA, V. J. Probabilidade - uma proposta de ensino - O uso do Teorema da Multiplicação de Probabilidade como um facilitador e integrador de diversas abordagens deste assunto. 2013. 48 f. Dissertação (Mestrado) - Universidade Federal de Goiás, Goiânia, 2013.

FREIRE, P. Pedagogia do Oprimido. 17ª ed. Rio de Janeiro, Paz e Terra, 1987.

GARCIA, C. M. Formação de professores - para uma mudança educativa. Tradução de Isabela Narciso. Portugal: Porto Editora, 1999.

GATTI, B. A. Políticas e práticas de formação de professores: Perspectivas no Brasil. XVI ENDIPE - Encontro Nacional de Didática e Práticas de Ensino - UNICAMP - Campinas: Junqueira\&Marin Editores. Livro 2, p. 16, 2012. (Arquivo digital)

GATTI, B. A; BARRETTO, E. S. S.; ANDRÉ, M. E. D. A.. Contexto contemporâneo, cultura, educação e políticas voltadas aos docentes. Políticas docentes no Brasil: um estado da arte. Brasília: UNESCO, 2011. Disponível em: $<$ http://unesdoc.unesco.org/images/0021/002121/212183por.pdf $>$ Acesso em: 29 ago. 2017.

GIL, A. C. Métodos e técnicas de pesquisa social. 2. ed. São Paulo: Atlas, 1989.

GRANDO, R. C. O Jogo suas possibilidades metodológicas no processo ensinoaprendizagem da matemática. 1995. 159 f. Dissertação (Mestrado) - Faculdade de Educação, Universidade Estadual de Campinas, Campinas, 1995.

GRANDO, R. C. O conhecimento matemático e o uso de jogos na sala de aula. 2000. 239 f. Tese (Doutorado) - Faculdade de Educação, Universidade Estadual de Campinas, Campinas, 2000.

LAVILLE, C; DIONNE, J. A construção do saber: manual de metodologia da pesquisa em ciências humanas. Tradução de Heloísa Monteiro e Francisco Settineri. Porto Alegre: Artmed, 1999.

LOPES, C. E. O Ensino de Estatística e Probabilidade na Educação Básica e a Formação de Professores. Cad. Cedes. Campinas, vol. 28. n. 74. p. 57 - 73, jan. /abr. 2008. Disponível 


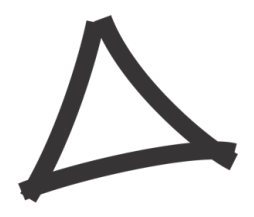

Revista Triângulo

www.seer.uftm.edu.br/revistaeletronica

em: $<$ https://sistemas.riopomba.ifsudestemg.edu.br/dmafe/subsistemas/professor/material/208 1973108_CELI\%20ESPASANDIN\%20LOPES.pdf> Acesso em 19 set. 2017.

MAGALHÃES, M. N. Desafios do Ensino de Estatística na Licenciatura em Matemática. In: SAMÁ, Suzi; SILVA, Mauren Porciúncula Moreira. (Org.). Educação estatística: ações e estratégias pedagógicas no ensino básico e superior. Curitiba, PR: CRV, 2015.

MARIM, V.; BARBOSA, A. C. I. Jogos Matemáticos: Uma proposta para o ensino das operações elementares. In: OLIVEIRA, C. C.; MARIM, V. (Org.). Educação Matemática: contextos e práticas docentes. Campinas, São Paulo: Editora Alínea, 2010.

MORENO, M. M. A.; CAZORLA, I. M.. Utilização do dotplot e do boxplot na aprendizagem da variabilidade estatística no Ensino Médio. In: SAMÁ, Suzi; SILVA, Mauren Porciúncula Moreira. (Org.). Educação estatística: ações e estratégias pedagógicas no ensino básico e superior. Curitiba, PR: CRV, 2015.

MOURA, M. O. O jogo e a construção do conhecimento. Série Ideias n. 10, São Paulo: FDE, 1992. p. 45-52 - disponível em <http://www.crmariocovas.sp.gov.br/dea_a.php?t=020> Acesso em 06 set. 2017.

ONUCHIC, L. R.; ALLEVATO, N. S. G. Pesquisa em Resolução de Problemas: caminhos, avanços e novas perspectivas. Bolema, Rio Claro, v. 25, n. 41, p. 73-98, 2011.

PIMENTA, S. G. Formação de professores: identidade e saberes da docência. In:

(Org.). Saberes pedagógicos e atividade docente. 8.ed. São Paulo: Cortez, 2012.

POLYA, G. A arte de resolver problemas: um novo aspecto do método matemático.

Tradução: Heitor Lisboa de Araujo. Rio de Janeiro: Interciência, 1995.

RIBEIRO, F. D. Jogos e modelagem na educação matemática. São Paulo: Saraiva, 2009.

SAVIANI, D. Formação de professores: aspectos históricos e teóricos do problema no contexto brasileiro. Revista Brasileira de Educação. v. 14 n. 40, 2009. Disponível em: < http://www.scielo.br/pdf/rbedu/v14n40/v14n40a12.pdf> Acesso em 13 set. 2017.

SMOLE, K. S. DINIZ, M. I. CÂNDIDO, P. Jogos de matemática de $\mathbf{1}^{\mathbf{0}}$ a $5^{\circ}$ ano. Cadernos do Mathema-Ensino Fundamental. Porto Alegre: Artmed, 2007.

SMOLE, K. S.; DINIZ, M. I.; PESSOA, N.; ISHIHARA, C. Jogos de matemática de $\mathbf{1}^{\mathbf{a}} \mathbf{a ~ 3}^{\circ}$ ano. Cadernos do Mathema-Ensino Médio. Porto Alegre: Artmed, 2008.

SMOLE, K.S.; DINIZ, M.I.; MILANI, E. Jogos de matemática do $6^{\circ}$ ao $9^{\circ}$ ano. Cadernos do Mathema. Porto Alegre: Artmed 2007. 